\title{
Construction and Practice of Surveying and Mapping Engineering Specialty Practice Teaching System
}

\author{
Xiange Cao \\ School of Surveying and Mapping Engineering \\ Heilongjiang Institute of Technology \\ Harbin, China \\ caoxiange@126.com
}

Jinling Yang

School of Surveying and Mapping Engineering Heilongjiang Institute of Technology

Harbin, China

\section{Weicheng Zhang}

School of Surveying and Mapping Engineering Heilongjiang Institute of Technology

Harbin, China

\author{
Jianguang Qu \\ School of Surveying and Mapping Engineering \\ Heilongjiang Institute of Technology \\ Harbin, China \\ 675644930@qq.com \\ Yingqi Guo \\ School of Surveying and Mapping Engineering \\ Heilongjiang Institute of Technology \\ Harbin, China \\ Haiyan Si \\ School of Surveying and Mapping Engineering \\ Heilongjiang Institute of Technology \\ Harbin, China
}

\begin{abstract}
The four dimensions are rule system dimension, organization dimension, practice base dimension and innovation dimension of Surveying and Mapping Engineering. "Four Dimensional Integration" practice teaching system is summarized in this article. The methods of construct practical teaching quality guarantee system is described in detail. The construction of whole process, all aspects, multi-method integrated practice teaching quality monitoring system is introduced. The implementation achievements of the "Four Dimensional Integration" practice teaching system is summed up, in order to provide references to general university in strengthening the practice teaching.
\end{abstract}

Keywords-Surveying and Mapping Engineering; Four Dimensions Integration; Practice teaching; Quality guarantee system; Quality monitoring system

\section{INTRODUCTION}

The Surveying and Mapping Engineering specialty of Heilongjiang Institute of Technology was founded in 1953, has nearly 60 years of history. In the process of more than 60 years of education, Surveying and Mapping Engineering specialty has been focusing on making the deep exploration and research on how to strengthen the practice teaching and has constructed the "Four Dimensions Integration" practice teaching system with distinct features. In the last few years, it takes the national characteristic specialty and provincial key specialty construction as an opportunity, combined with the construction of key laboratory of colleges and universities in Heilongjiang province, gradually strengthened the students' practical ability training, after years of implementation, and has achieved certain success and achievement.

\section{CONSTRUCTION OF "FOUR DiMENSIONS INTEGRATION" PRACTICE TEACHING SYSTEM}

The "Four Dimensions" of Surveying and Mapping Engineering "Four Dimensions Integration" practice teaching system refers to the rule system dimension, organization dimension, practice base dimension, innovation dimension; "Integration" refers to each practice teaching dimension although independent, but really influences each other and complements each other to form a complete practice teaching system [1].

\section{A. Rule System Dimension}

Rule system dimension refers to the practice teaching interior environment construction. In view of the learning content and requirements of different grades of Surveying and Mapping Engineering specialty in the undergraduate course four years in school, each grade, respectively, set up a corresponding appraisal and incentive mechanism. To freshman, the professional introduction courses should be emphasized, in order to make students understand the professional background as soon as possible and clear the direction of professional study, and the assessment of excellent rate of courses should also be mainly emphasized. To sophomore, more attention should be paid to students' basic skills training, and the pass rate of College English Test Band 4 and National Computer Rank Examination should be assessed. To junior, cultivation of students' scientific and cultural quality should be focused, and the competition of technological and cultural knowledge, English Test Band 6 and the computer level should be the main assessment contents. To senior, more attention should be paid to develop student's own quality, the main assessment contents are student's Graduate entrance 
enrollment rate, employment quality and employment rate, etc., and progressively achieve full four-year university students incentive mechanism.

In order to ensure the smooth implementation of full fouryear university students incentive mechanism, the corresponding quantitative assessment index system and assessment standards need to be set up, such as the course credits and index system of quality development and innovation of science and technology activities should be made; Inspector mechanism on undergraduate students and special immortal should be implemented, the fourth grade student tutor system should combined with the ideological work, graduation design and of employment guidance; The reward mechanism of merit student, science and technology innovation should also be implemented; Graduation designing should adopt double system and double tutorial system, the selected topic should closely with engineering and scientific research projects, the full-time experiment technology personnel of laboratory should apply performance appraisal and formulate detailed assessment quantitative standards [2].

\section{B. Organization Dimension}

Organization dimension refers to the organization construction of practice teaching. According to the characteristics of the practice teaching and the aim to guarantee and promote the operation of the practice teaching, the province and school two levels experiment teaching center platform were established, an efficient steering committee with executive ability and the ability to promote experiment teaching has been established. The experiment teaching steering committee composed by the institute leaderships, full time and part-time teachers and business experts, and is responsible for the study and decision-making of the specialty issues of the laboratory and the experiment teaching, and also responsible for the decision and approval of various laboratory and experimental teaching management systems. Full-time theory teaching teachers and experimental technicians will share the experiment teaching tasks, work together and achieve complementary advantages, achieve mastery through a comprehensive experiment teaching and theory teaching [2]. Three scientific and technological innovation organizations were established (Surveying and Mapping Engineering association, GIS Engineering association, GPS association) which were managed by students themselves and various kinds of scientific and technological innovation activities are carried out on a regular basis. Specialized course teachers usually as the consultant of association.

\section{Practice Base Dimension}

Practice base dimension refers to the construction of practice teaching base off and in campus. Surveying and Mapping Engineering School insists the cooperation of production and scientific research with departments or institutes of surveying and mapping, surveying and mapping unit of Geomatics and aims to attain mutual benefit, win-win results. University-enterprise cooperation committee was established which was concrete conducted by Surveying and Mapping Engineering School. At present, Surveying and Mapping Engineering School has set up 13 off-campus internship and practice base, and the school and enterprises regular have cooperation seminar to summarize cooperation experience, in order to gradually improve and expand cooperation. Every year, according to the practice tasks the school regularly organizes the student to the production practice base to complete production tasks. The enterprise experts are regularly invited to conduct lectures with combination of engineering background and engineering practical problems to students and faculties. A provincial experimental demonstration center was set up, the center implements the open experimental teaching policy, the open contents range from time, content to the experiment object. The network open laboratory management information platform was set up, students can online make the experiment teaching reservation, instruments used reservation, etc. The college students' innovative experiment platform was established, the proportion of the enhancing and innovative experiment is gradually increased, and by writing the teaching book of measurement instruments materials solved the problem of the lack of open experimental teaching materials.

\section{Innovation Dimension}

Innovation dimension refers to the practice teaching innovation system construction. By constructing the practice teaching innovation system, students consciously carry out the project and participate in a variety of disciplines races, science and technology innovation contests. Specialty teachers instruct outstanding undergraduate students to participate in the laboratory construction, scientific research and technology services, with the use of advanced instruments and equipment of Surveying and Mapping and Surveying and Mapping software's secondary development to drive students' innovative experiments. Students are encouraged from manpower and material resources to participate in national and provincial innovation activities and all kinds of competitions, and combine with these competitions school or college level activities are carried out. Undergraduate students are encouraged to participate in the teachers' scientific research projects which promote the undergraduate's innovation and raise the application ability [3].

"Four Dimensions Integration" practice teaching system consolidates students' knowledge, broadens students' marketability, improves students' operating ability, cultivates students' quality, and forms the characteristics that complex class of surveying and mapping engineering technical talents with engineering quality.

\section{CONSTRUCTION OF PRACTICE TEACHING QUALITY GUARANTEE SYSTEM}

\section{A. Actively Explores the Reform of Practice Teaching Content and Practice Teaching Method of Effective Mechanism and Builds and Perfects the Curriculum Development Platform Gradually.}

Taking the comprehensive reform of higher education and "Excellence plan" as the backing, deepen the construction of "Quality course" and "Quality materials" and around the teaching idea, curriculum system, teaching content and 
teaching method and other aspects gradually carry out professional course construction and reform.

Through "Teacher Forum" to build positive interaction between scientific research and engineering practice and teaching, according to the characteristics of subjects to hire engineers and well-known experts both at home and abroad to give lectures and hold various lectures. In recent 3 years, 15 reports are made by inviting famous experts to our institute; the report contents are very extensive, covering various fields of Surveying and Mapping Engineering. Through the "Teacher Forum" not only the forefront of scientific theory knowledge and the latest engineering practice situation are conveyed to students, but also makes up for the relative lag of teaching contents. At the same time, by the teacher's words and deeds carrying out influence on students' life and scholarly and other aspects [4].

Encourage teachers devoted to the education research and carry out more teaching research achievements and more actively promote the research-oriented teaching. In recent 5 years, Surveying and Mapping Engineering School encourages teachers and management personnel do research emphasis on the aspects such as curriculum, textbooks, teaching contents and methods, teaching management reform and research and talent cultivation system construction of Surveying and Mapping Engineering, in the same time, intensify the education teaching research project declaration and have won 15 teaching reform projects in the last 3 years.

\section{B. Gradually Explores Teachers' Teaching Ability \\ Development Effective Mechanism and Reasonable Builds An Incentive Mechanism of Teachers' Teaching Development Platform.}

Actively promote the "Double Type" teachers teaching ability construction. Surveying and Mapping Engineering School has organized practice teaching teachers go out learning, take an active part in training, research, and practice teaching seminars and so on nearly 100 person-time, funding practice teaching teachers published research papers and filing for a patent for invention, the software copyright nearly 30, all of them play a good role on enhancing teachers' engineering practice ability. Actively hire Geomatics Academicians and well-known scholars as the teachers come to school giving lectures to teachers and students and let them feel "masters" teaching style and art, and play the role of "renowned scholars" model and demonstration. Implementing the special practical skills training "talent strong teaching plan", actively promotes the "double type" teachers teaching ability construction [4].

Surveying and Mapping Engineering School established the effective teaching incentive mechanism and gradually increases the intensity of commendation and reward for good teachers, also strengthens the daily guidance of middle-aged and young teachers, respectively set up the "Outstanding Teacher Award", "Teaching Experts Award" and other awards, through these measures to improve the interests of teachers engaged in teaching. For those teachers whose teaching quality and level temporarily can not meet the requirements, we strengthened the "guidance" to them, and through efforts to organize expert group face to face interaction, rectification and help to strengthen and promote the whole school teaching level [4].In recent 3 years five teachers have respectively won the "outstanding teacher award" and "Teaching Experts award".

Actively explores the teaching ability development training mode of middle-aged and young teachers. Fresh graduates and those from enterprises with no experience in teaching must attain the pre-service training, only after obtained the approval certificate that they can to teach undergraduate courses; encourage young teachers to participate in the high school teachers' pre-service training on the education theory. School secondary supervise teachers every semester manage once teaching basic skills training of young teacher, and also organize one-on-one "teach, help, encourage" activities between old teachers and young and middle-aged teachers, and from rule point guarantees the basic quality of teachers and basic level of teaching. The overall quality of teachers can be improved through these measures. On the basis of "teach, help, encourage" mechanism, in July 2011, the young and middleaged teachers won a first prize and a second prize in "National Universities Surveying and Mapping Lecture Competition of Young Teachers" in each one, and won a third prize in "The First National Universities GIS Professional Young Teachers Lecture Contest" in 2012.

\section{Actively Explores Students' Effective Learning Mechanism and Builds the Development Platform Which Can Effectively Improve Students' Innovation and Practice Ability.}

Optimizing the talent cultivation plan, create innovative environment. Based on extensive discussion and investigation, a comprehensive revision was taken out about 2007 talent cultivation plan. The new talent cultivation plan is revised based on "strengthening the foundation, strengthening practice, building a platform, optimizing the structure, focus on innovation, insisting on the combination of unity and diversity" as a whole train of thought. The new talent cultivation plan emphasis on creating a good environment for college students' innovation consciousness, innovation ability and practice ability; at the same time, the following three platforms are constructed: general education, specialty basic education, comprehensive education (ability development and innovation and entrepreneurship education); to the new talent cultivation plan, the flexible educational system construction is deepened, the self-study course is added, the cultivation of students' autonomous learning ability is strengthened, 2 4 new credits are established aim to strengthen the cultivation of students' innovation ability.

Strengthening the construction of experimental teaching center and construction of the students' experimental ability development platform. Strengthening the construction of experimental teaching demonstration center and innovative experiment project, now our school has constructed one experimental teaching demonstration center of the Heilongjiang province, and one college students' practice teaching offcampus base of Heilongjiang province.

Perfect the three-level network science and technology competition, and deepen the students' innovative and practical ability. Based on adhere of practice teaching characteristic, the 
cultivation of students' innovation ability is deepened. Through the construction of teaching base, the three level college students science and technology competition network of school, Heilongjiang province and national levels are constructed, which provide students with special skills and personality development platform. In the last 3 years, various achievements of science and technology competition are gained: on the one hand, students' participating coverage expanded year by year, more than 300 people in the last 3 years attended all kinds of competitions, this helps to promote the development of students' personality and special skills, also played a very good role in training the students to pursue outstanding competitive consciousness and team spirit of cooperation; on the other hand, these competitions played a good promoting role in discovering, selecting and cultivating the excellent talents.

\section{CONSTRUCTION OF PRACTICE TEACHING MONITORING SYSTEM}

In order to ensure the normal operation of "Four Dimensions Integration" practice teaching system, a practical teaching quality monitoring system of Surveying and Mapping Engineering specialty is build, which can be summarized as: whole process, all aspects, multi-method integrated practice teaching quality monitoring system.

The specific contents of the system are as follows:

\section{(1) Whole process}

"A Mainline, Three Phases" whole-process control model is constructed. "A Mainline" means that "monitoring the full process quality, improving the practice teaching quality"; "Three Phases" means that according to semester calendar formed three important stages of quality monitoring: first stage (6-7 week), checking practice teaching and feedback information on the 8th week, and this can conducive to teachers to improve the subsequent practice teaching work; second stage (13th week), "students assess the teaching quality of teacher, and teachers assess the learning conditions of students and management of school"; third stage (18th week), school departments and experts inspect and assess the practical teaching quality of every school [4]. At the same time, process quality management patterns are also used in every practical teaching links, for example, graduation design formed a process of from title opening, to the mid-term review, presentation and excellent paper reply.

\section{(2) All aspects}

Based on the development goals of practice teaching quality, practice teaching quality evaluation criteria are explored on the various aspects of teaching, the quality evaluation criteria of practice teaching, curriculum design, graduate design, assessment and all practice teaching aspects have been established one by one, and formed a teaching quality evaluation standard system. Each semester, every practice teaching link will be evaluated on quality according to the evaluation criteria.

\section{(3) Multi-method}

Practical teaching quality evaluation model of Multimethod is build. At present, the practice teaching quality evaluation methods of Surveying and Mapping Engineering specialty which are under implementation as following: practice teaching order check of the opening weeks by the leadership of the school department, expert on-site inspect and observation, interview on students and teachers, questionnaire survey [4]. Practice teaching evaluation mode is formed by the combination of expert appraisal practice teaching quality and the student evaluation of teacher teaching quality.

\section{ACHIEVEMENTS}

\section{A. A Number of Influential Teaching and Research Results Are Gained.}

Through the implementation of the "Four Dimensions Integration" practice teaching mode, Surveying and Mapping Engineering specialty was selected by the ministry of education to pilot construction in 1994, after five years of construction, the specialty was identified as the national demonstration of higher engineering college specialty by the ministry of education in 1999. Surveying and Mapping Engineering specialty was identified as the key construction specialty of Heilongjiang province in 2000 , and passed the intermediate inspection which was organized by provincial education department in 2003. The specialty was identified as the provincial key construction professional in 2005, and was named the provincial characteristics specialty in 2007 , and was named the national characteristic specialty in 2008. Also, the specialty was identified as pilot professional construction of applied undergraduate colleges and universities in Heilongjiang province in 2009, and subsequently the specialty was identified as characteristic specialty construction experimental unit of applied undergraduate colleges and universities in Heilongjiang province in 2010 , in 2011 , the specialty passed the provincial key professional assessment acceptance and obtained outstanding key specialty title.

\section{B. The Strength of Practice Teaching Platform Is Enhanced.}

A provincial experimental teaching demonstration center of Surveying was built, the central and local governments project, the provincial experimental teaching demonstration center project and other construction projects were applied, about 2,000 million Yuan are invested to the construction of laboratory, the experimental equipments are update and the high technology is introduced, a networking, open practice teaching management information platform was set up.

In December of 2012, the experimental teaching demonstration center of Surveying passed the demonstrations center acceptance which was organized by Heilongjiang Provincial Education Department, and accessed the alike evaluation of experts. At present, 13 stable bases of teaching practice, social practice and comprehensive cooperation are created, which can meet 300 students' internship and social practice of each semester; a group of off-campus teachers are hired.

The practice base, which was build by Surveying and Mapping Engineering School cooperate with Surveying and Mapping Geographic Information Bureau in Heilongjiang, in 2012, was identified by Ministry of Education as college 
campus practice education base. In recent years, with the use of engineering technology services and undertake research projects we gradually combined theoretical teaching of related courses to led the students in-depth projects, and stimulate the enthusiasm of students, and improve the practical application of skills.

\section{Teaching Methods Are Reformed, Project Teaching Is Implemented.}

"Cramming" teaching mode of the past in which the teacher as the center are reformed, the teaching mode of taking students' innovative ability training as the center, the project and scientific research achievements throughout the process of teaching are gradually adopted in the practice teaching, all the practice teaching of specialized courses and professional basic course adopting multimedia courseware assisted instruction, and in the courseware the actual engineering case are constantly updated and added. At the same time, during teaching, heuristic and discussion-based teaching methods are adopted. Theory teaching full-time teachers and experimental technicians will share the experiment teaching tasks, work together and achieve complementary advantages, achieve mastery through a comprehensive experiment teaching and theory teaching. Also, 3 to 4 times engineering visit combined courses are arranged in extracurricular. Students' interests in specialized fundamental course and specialized course are increased and course excellence rate increased year by year.

\section{The Overall Quality of Student Is Improved.}

Surveying and Mapping Engineering specialty student's excellent rate of achievement, the pass rate of College English Test Band 4, College English Test Band 6 are enhanced year by year, school acceptance rate increases every year, and more than half of them accepted by "211" and "985" universities.

In the past 3 years, more than 40 students are awarded a prize in the "Challenge Cup", the national and provincial mathematical modeling, mapping equipment operation skills competition, English contest, etc. In the past 3 years, based on the strengthening of practice and participate in the scientific research, nearly 25 academic papers are published which were wrote by students themselves.

At present, the graduates are in short supply and the employment rate has remained above $97 \%$ for many years.

\section{CONCLUSION}

Practice teaching is an effective way to consolidate theoretical knowledge and deepen understanding of the theory, and it is the important link to train professional talents with innovative consciousness, and also the important platform of cultivating the students on how to master the scientific method and raise practice ability [5]. By the implementation and application of Surveying and Mapping Engineering specialty, it showed that the "Four Dimensions Integration" practice teaching system is obviously effectiveness. Now, the Surveying and Mapping Engineering specialty has become one of the national characteristic specialties and students' comprehensive ability are enhanced, the students' basic knowledge and professional knowledge are further strengthened, peers recognition are gained in the process of employment.

\section{ACKNOWLEDGMENT}

This work was financially supported by the Heilongjiang Province higher education teaching reform project (JG2201201232), Heilongjiang Province higher education teaching reform project (JG2013010480), Heilongjiang Province Educational Programs (GBD1211052), "Twelfth Five-Year" Plan project of Higher Education Scientific Research in Heilongjiang Province (HGJXHB2110939), Heilongjiang Institute of Technology education teaching reform project (JG2012029), Standardization of Heilongjiang Institute of Technology teaching and research section (department) construction project (2012).

\section{REFERENCES}

[1] C. M. Wang. H. Wang. Exploration and Practice of "Four in One" Practical Teaching Mode. Journal of Yangling Vocational \& Technical College, vol.2, pp.78-81, June. 2011.

[2] X.Huang. Construction of Four Dimensions Integration teaching system, building the brand specialty. The second session of the National Forestry Colleges Education Reform and Innovation Forum, http://jgcxlt.njau.edu.cn/webnews/display.do?wnid=71\&newsid=87,201 1.11.9.

[3] P.Yang. Construction of Four Dimensions Integration teaching system, laid the basis for justifying engineering majors, Nanjing Forestry University.

http://nlbbjb.cuepa.cn/index.php?release_id=31389\&paper_id=115311, 2012.5.15.(4).

[4] S. D. Xue. Q. F. Li. Z. Q. Li.Theory and Practice of "Four Dimensions Integration" Teaching Quality Assurance System. China University Teaching, vol.6, pp.64-67, 2008.

[5] L. T. Zhou. Construction of Practical Teaching System of Colleges Specialty. Educational Review, vol.1, pp.58-60, 2007. 